Int. J. Biometeor. 1972, vol. 16, number 4 , pp. 375-387

\title{
Maximal Oxygen Uptake, Sweating and Tolerance to Exercise in the Heat
}

by

\author{
J. E. Greenleaf*, B. L. Castle and W.K. Ruff
}

\section{NTRODUCTION}

The physiological mechanisms that facilitate acute acclimation to heat have not been fully elucidated, but the result is the establishment of a more efficient cardiovascular system to increase heat dissipation via increased sweating (Wyndham et al., 1968) that allows the acclimated man to function with a cooler internal environment and to extend his performance (Rowell et al., 1967). Men in good physical condition with high maximal oxygen uptakes generally acclimate to heat more rapidly and retain it longer than men in poorer condition (Bean and Eichna, 1943; Eichna et al., 1945). Also, upon first exposure trained men tolerate exercise in the heat better than untrained men (Greenleaf, 1964; Piwonka et al., 1965). Both resting in heat and physical training in a cool environment confer only partial acclimation when first exposed to work in the heat (Bean and Eichna, 1943; Strydom et al., 1966). These observations suggest separate additive stimuli of metabolic heat from exercise and environmental heat to increase sweating during the acclimation process. However, the necessity of utilizing physical exercise during acclimation has been questioned. Bradbury et al. (1964) have concluded exercise has no effect on the course of heat acclimation since increased sweating can be induced by merely heating resting subjects.

Preliminary evidence suggests there is a direct relationship between the maximal oxygen uptake and the capacity to maintain thermal regulation, particularly through the control of sweating (Astrand, 1960; Kozlowski and Saltin, 1964; Saltin and Hermansen, 1966). Since increased sweating is an important mecha$\mathrm{nis}$ for the development of heat acclimation, and fit men have high sweat rates, it follows that upon initial exposure to exercise in the heat, men with high maximal oxygen uptakes should exhibit less strain than men with lower maximal oxygen uptakes. The purpose of this study was (a) to determine if men with higher maximal oxygen uptakes exhibit greater tolerance than men with lower oxygen uptakes during early exposure to exercise in the heat, and (b) to investigate further the mechanism of the relationship between sweating and maximal work capacity.

\section{PROCEDURE AND METHODS}

Seven healthy young men with maximal oxygen uptakes between $2.83 \mathrm{1} / \mathrm{min}$ $[42 \mathrm{ml} /(\min . \mathrm{kg})]$ and $5.97 \mathrm{l} / \mathrm{min}[66 \mathrm{ml} /(\mathrm{min} . \mathrm{kg})]$ were employed as subjects (Table 1). After determination of their maximal oxygen uptakes, they were tested in pairs in an environmental chamber and underwent one $2-\mathrm{hr}$ control exercise

*) Laboratory of Human Environmental Physiology, National Aeronautics and Space Administration, Ames Research Center, Moffett Field, California 94035 , USA.

Received 10 August 1972 


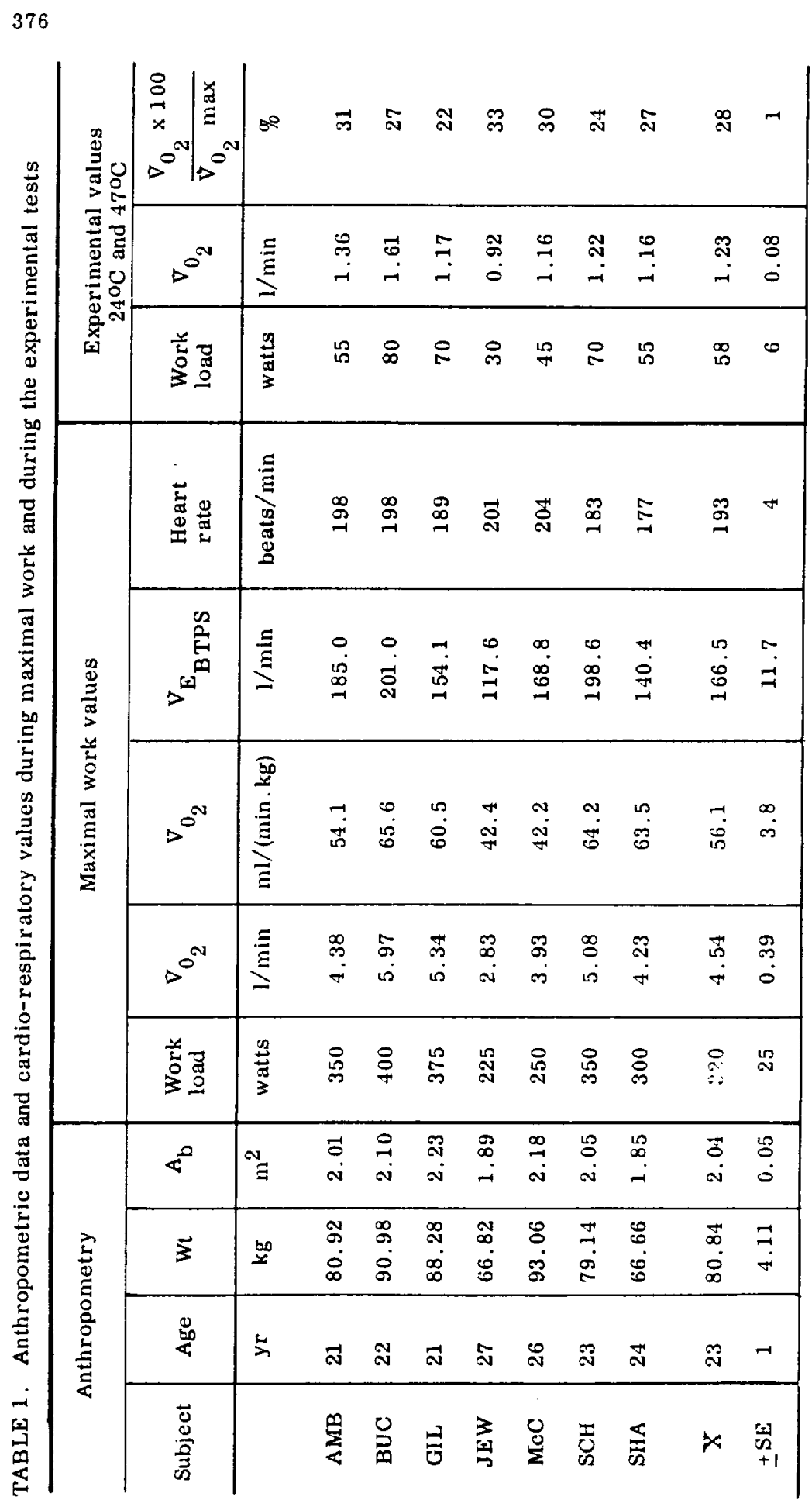


test on a Monark bicycle ergometer at $24^{\circ} \mathrm{C} \mathrm{T}_{\mathrm{db}}$. Each pair of subjects then underwent three 2-hr acclimation exposures at $47^{\circ} \mathrm{CT}_{\mathrm{db}}$ with one day of rest between exposures (Table 2). During all tests the subjects exercised at a relative oxygen uptake $\left(\dot{\mathrm{V}}_{02} \times 100 / \dot{\mathrm{V}}_{02} \mathrm{max}\right)$ of $28 \pm 1 \%$ (Table 1 ). Workloads that gave approximately the same relative oxygen uptakes were employed instead of constant absolute workloads to provide comparable "internal stress" and similar elevation of core temperature for each subject. The environmer.cal conditions provided constant "external stress" and comparable levels of skin temperature.

TABLE 2. Average environmental conditions during the experiment

\begin{tabular}{l|c|c|c|c|c}
\hline & $\mathrm{T}_{\mathrm{db}}$ & $\mathrm{T}_{\mathrm{wb}}$ & $\mathrm{rh}$ & $\mathrm{P}_{\mathrm{H}_{2} \mathrm{O}}$ & $\mathrm{T}_{\mathrm{g}}$ \\
\hline & ${ }^{\circ} \mathrm{C}$ & ${ }^{\circ} \mathrm{C}$ & $\%$ & $\mathrm{~mm} \mathrm{Hg}$ & ${ }^{\circ} \mathrm{C}$ \\
Control test & 24 & 16 & 44 & 10 & 21 \\
Acclimation test no 1 & 48 & 32 & 34 & 27 & 47 \\
Acclimation test no 2 & 48 & 33 & 38 & 31 & 47 \\
Acclimation test no 3 & 47 & 33 & 41 & 32 & 47 \\
\hline
\end{tabular}

In all tests turbulent air motion varied from 12 to $15 \mathrm{~m} / \mathrm{min}$.

Expired gas was collected in meteorological balloons and the $\mathrm{O}_{2}$ and $\mathrm{CO}_{2}$ concentrations were determined immediately with Beckman E2 and Beckman IR 215 analyzers. Analyzer calibrating gases were calibrated with the micro-Scholander technique (Scholander, 1947). Oxygen uptake was calculated with data from the nomogram of Dill and Fölling (1928). The reproducibility of duplicate $\nabla_{02}$ measurements averaged $\pm 0.02 \mathrm{l} / \mathrm{min}$. The $175 \mathrm{ml}$ dead space in the modified OtisMcKerrow respiratory valve was included in the calculation of $V_{E}$ from $V_{E_{\text {ATPS }}}$. Heart rate was determined from the continuous EKG ${ }^{E}$ BTPS record.

Rectal $\left(\mathrm{T}_{\mathrm{re}}\right)$, auditory canal $\left(\mathrm{T}_{\mathrm{ac}}\right)$ and skin temperatures were measured with YSI series 400 thermistors and recorded on a Digitek thermometer; system accuracy was $\pm 0.05^{\circ} \mathrm{C}$. The rectal thermistor $w$ as inserted $17 \mathrm{~cm}$ and the six skin thermistors were fixed to spring clips attached to plastic rings that allowed free evaporation of sweat around each thermistor. The skin thermistors were located on the medio-lateral arm, medio-lateral forearm, upper abdomen, subscapular region, medio-anterior thigh and medio-lateral leg. Each skin thermistor reading was multiplied by the proportion of total surface area represented by that thermistor and the sum of the six products was the mean skin temperature $\left(\overline{\mathrm{T}}_{\mathrm{S}}\right)$. Auditory canal temperature was measured 8 to $10 \mathrm{~mm}$ from the tympanic membrane (Greenleaf and Castle, 1972). Total body sweat rate was calculated from changes in body wt measured on a platform balance $( \pm 5 \mathrm{~kg}$ ) at halfhourly intervals taking into account voluntary tap water consumption $\left(37^{\circ} \mathrm{C}\right)$ but not respiratory gas exchange.

The criteria for terminating a test (tolerance time) were either a $\mathrm{T}_{\mathrm{re}}$ of $40^{\circ} \mathrm{C}$, a maximal heart rate for one min, or the subject's request to stop. The main signs and symptoms of most subjects at the termination of work were those of classical heat exhaustion: fatigue, nausea, excessively high heart $r$ ates, syncope during the rest periods, dizziness, chills and shortness of breath. 


\section{RESULTS}

\section{MAXIMAL OXYGEN UPTAKE AND TOLERANCE}

The results indicate essentially no demonstrable positive relationship between maximal oxygen uptake and tolerance to $\mathrm{T}_{\mathrm{db}} 47^{\circ} \mathrm{C}$ while working at an average workload of $58 \mathrm{~W}$ and a relative oxygen uptake of $28 \%$ (Fig. 1). and subject $\mathrm{JEW}$, with highest maximal oxygen uptake of $65.6 \mathrm{ml} /(\mathrm{min} . \mathrm{kg})$, and subject JEW, with the second lowest maximal oxygen uptake of 42.4 $\mathrm{ml} /(\mathrm{min} . \mathrm{kg})$, were exposed simultaneously and their tolerances for each of the three acclimation exposures were practically the same: subject BUC tolerance times were 55,85 and $85 \mathrm{~min}$; subject JEW times were 55,75 and 85 min, respectively (Fig. 1, Table 3).

During the first acclimation exposure subject AMB was able to work for $120 \mathrm{~min}$ (100\% tolerance), subject SHA completed $115 \mathrm{~min}$ and subject McC, who had the lowest maximal oxygen uptake $[42.2 \mathrm{ml} /(\mathrm{min} . \mathrm{kg})$,] stopped at $85 \mathrm{~min}$. Three other subjects (BUC, SCH, GIL) with high maximal oxygen uptakes had first exposure tolerances of $55 \mathrm{~min}$ or less.

During the second acclimation exposure, the tolerance of subject AMB decreased from $120 \mathrm{~min}$ on the first exposure, the tolerance of subject SHS dropped from 115 to $70 \mathrm{~min}$ and $\mathrm{MCC}$ from 85 to $70 \mathrm{~min}$. Conversely, those subjects with the lowest first exposure tolerances all had greater tolerance during the second exposure: GIL went from 50 to $55 \mathrm{~min}$, SCH increased from 50 to $75 \mathrm{~min}$ and $\mathrm{JEW}$ from $55 \mathrm{~min}$ (he was stopped because his heart rate reached 200 beats $/ \mathrm{min}$ ) to $75 \mathrm{~min}$. The average tolerance of $82 \mathrm{~min}$ was highest during the third acclimation exposure. It should be emphasized that the second exposure tolerances of subjects AMB, SHA and McC (55, 70 and $70 \mathrm{~min}$, respectively), who had the greatest first exposure tolerances, were not appreciably different than the second exposure tolerances of subjects GIL, SCH and JEW (55, 75 and $75 \mathrm{~min}$, respectively), who had the lowest first exposure tolerances. In all but two exposures termination was by voluntary withdrawal.

\section{COMPARISON OF SUBJECTS WTH HIGH AND LOW MAXIMAL OXYGEN UPTAKES}

A comparison of average tolerance time, $\Delta \mathrm{T}_{\mathrm{re}}, \Delta$ heart rate and terminal heart rates between the two subjects with the highest maximal oxygen uptake (BUC and SCH, $\bar{X}$ area $=2.08 \mathrm{~m}^{2}$ ) and the lowest maximal agen uptake ( $\mathrm{JEW}$ and $\mathrm{McC}, \overline{\mathrm{X}}$ area $=2.04 \mathrm{~m}^{2}$ ) is presented in Fig. 2. During the first acclimation exposures (Al), the low max $V_{02}$ pair had greater tolerance, $58 \mathrm{~min}$, compared with $44 \mathrm{~min}$ for the high $\max \mathrm{V}_{02}$ pair; the values for the other three variables for the two pairs were essentially the same.

During the second acclimation exposure (A2), the high $\max v_{02}$ pair had a $\Delta \mathrm{T}_{\mathrm{re}}$ of $2.55^{\circ} \mathrm{C}$ compared with $1.98^{\circ} \mathrm{C}$ for the low group (Fig. 3 ). Terminal heart rates were 10 beats/min higher in the low pair.

During the third acclimation exposure (A3), while tolerance time, $\Delta \mathrm{T}_{\mathrm{re}}$ and terminal heart rates were essentially the same, the $\Delta$ heart rate for the low maximum pair was reduced 25 beats/min compared with the high maximum pair due to elevated resting heart rates in the former (Fig. 2, Table 3). From these data it is clear that, when working at the same relative load, the high capacity pair has no appreciable advantage in tolerance over the low
capacity pair during early exposure to heat. 
ship be-

ing at an

g. 1).

(min. kg),

f 42.4

- each of

BUC

55,75 and

rork for

ject $\mathrm{McC}$,

ped at

1 oxygen

AMB

ibject SHS

sely, those

tolerance

creased

his heart

$82 \mathrm{~min}$ was

sized that

j5, 70 and

ices, were

ubjects

ie lowest

as by volun-

d terminal ygen uptake

in uptake

ig the first

erance,

llues for the $\therefore$

pair had a

Terminal

e, $\Delta T_{\text {re }}$ and for the low maximum

able 3).

tive load,

over the low

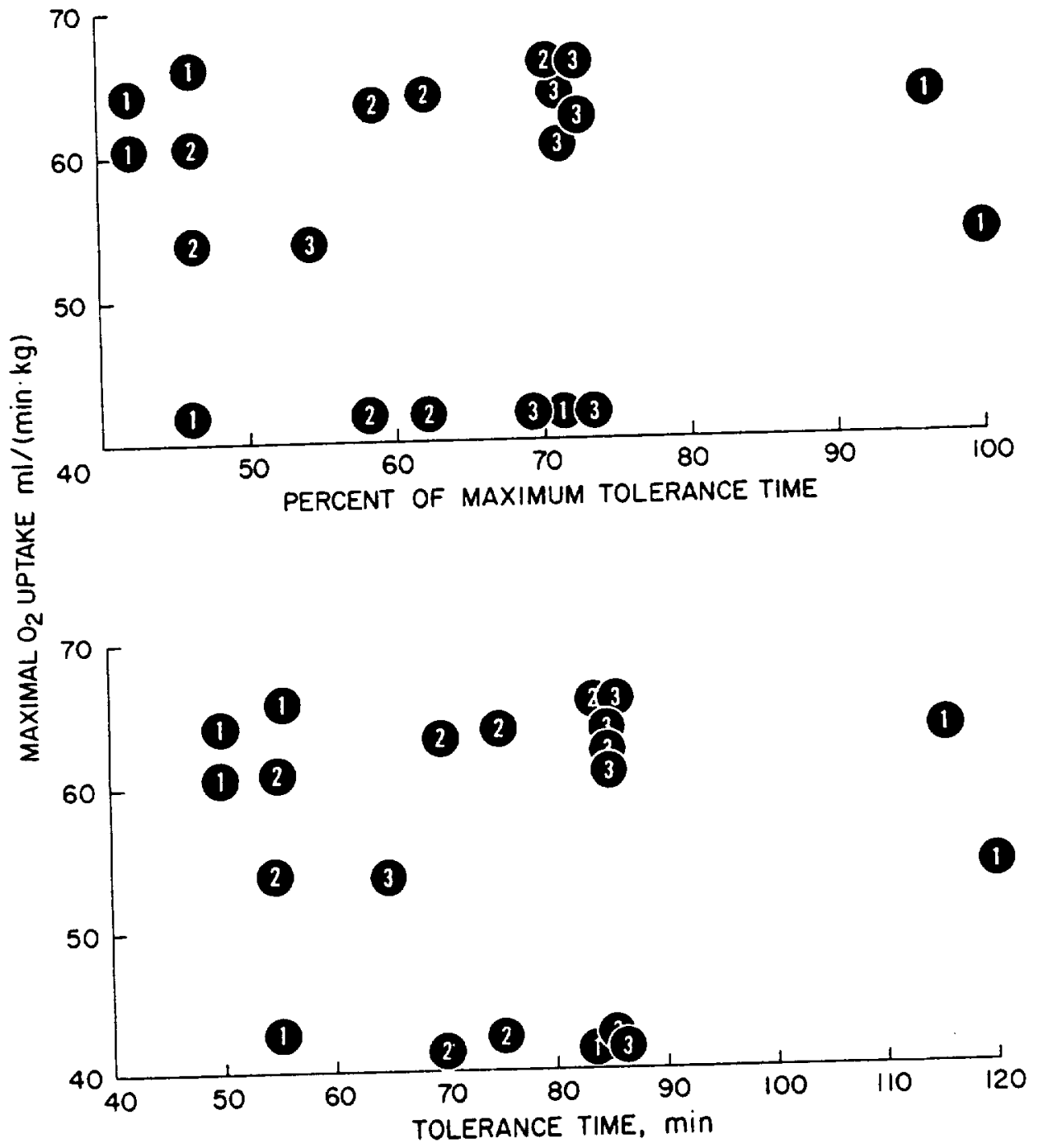

Fig. 1. Individual values for maximal oxygen uptake and tolerance time expressed as \% of maximal for the first (1), second (2) and third (3) heat exposures. 


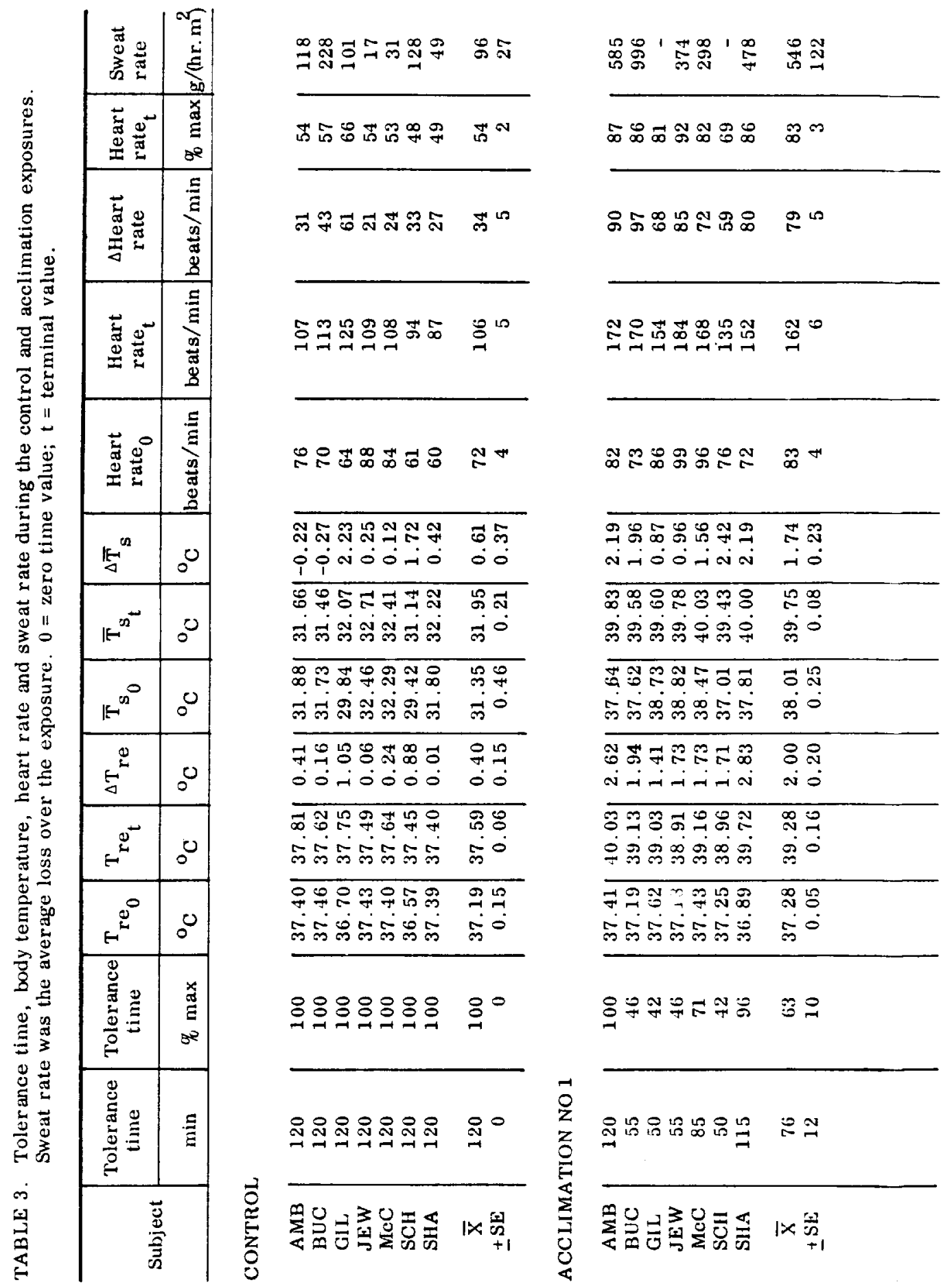



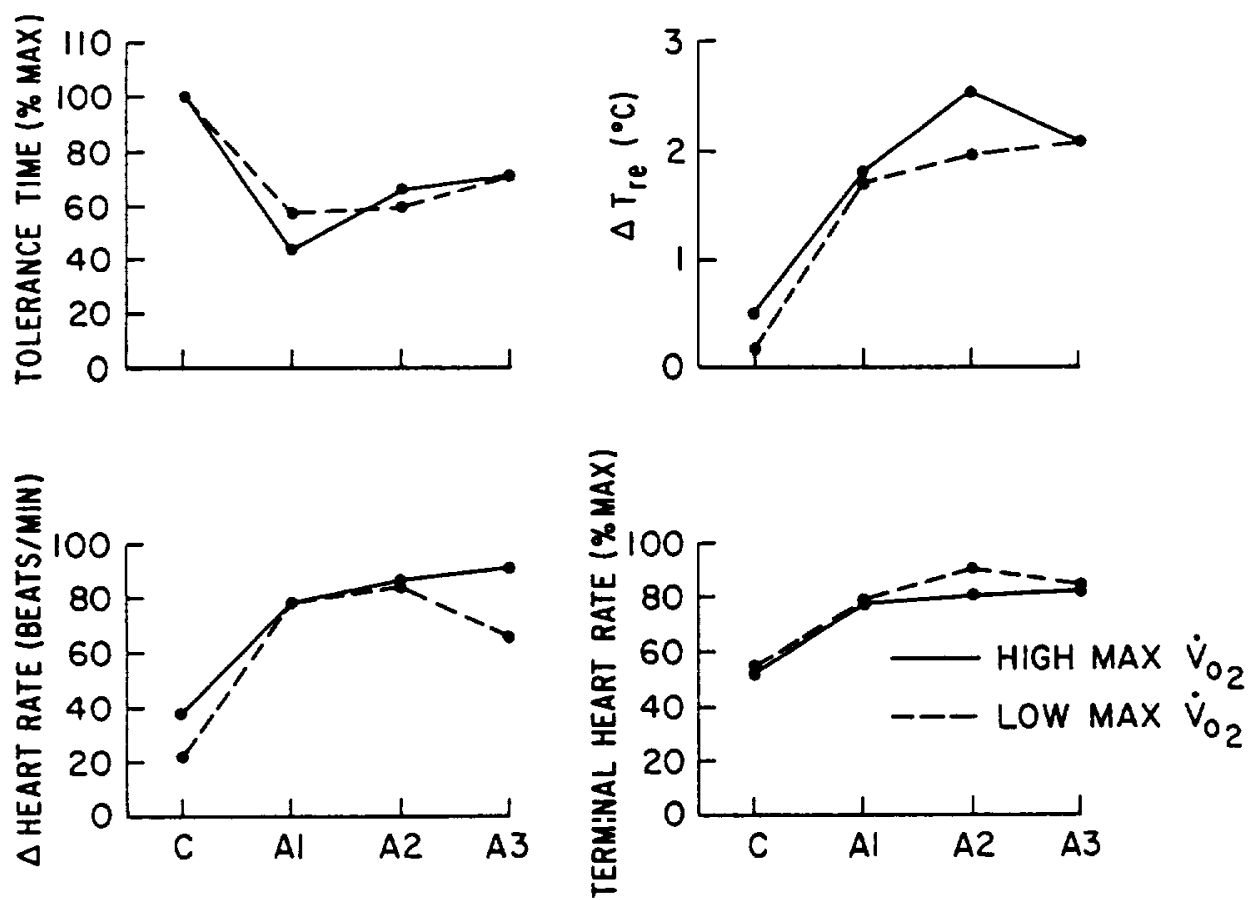

Fig. 2. Comparison of average tolerance time, $\Delta$ heart rate, $\Delta$ rectal temperature and terminal heart rate (\% of maximum) between the two subjects with the highest $\mathrm{V}_{02}$ (BUC and $\mathrm{SCH}$ ) and the two subjects with the lowest $\max V_{02}$ (JEW and McC).

$\mathrm{C}=$ control, $\mathrm{Al}=$ acclimation no 1 , etc.

\section{MAXIMAL OXYGEN UPTAKE AND SWEAT RATES}

In five of the seven subjects sweat rates progressively increased from the first through the third acclimation exposures (Fig. 3, Table 4). Of particular interest is the relationship between "maximal" sweat rates (those measur-u during the second half-hour period) and maximal oxygen uptake (Fig. 3). The solid line is the average of the $C, A 1, A 2$ and $A 3$ sweat rates. The missing data during the first acclimation exposure in subjects SCH and GIL were due to the inability of these men to complete the second half-hour work period. During the $24^{\circ} \mathrm{C}$ control test, the average second period sweat $r$ ate in the two high max $\nabla_{02}$ subjects

$\left[178 \mathrm{~g} /\left(\mathrm{hr} \cdot \mathrm{m}^{2}\right)\right]$ was much greater than the sweat rate in the two low maximum subjects $\left[24 \mathrm{~g} /\left(\mathrm{hr} \cdot \mathrm{m}^{2}\right)\right]$. This difference was also present during the three acclimation exposures (Table 4 ). In general, during the three acclimation exposures, the maximal oxygen uptake, expressed as $\mathrm{ml} /(\mathrm{min} \cdot \mathrm{kg})$, was proportional to the swe at rate expressed as $\mathrm{g} /\left(\mathrm{hr} \cdot \mathrm{m}^{2}\right)$.

\section{GE NE RAL RESULTS}

In the control experiment the average $\Delta \mathrm{T}_{\mathrm{re}}$ was $+0.40^{\circ} \mathrm{C}, \Delta \overline{\mathrm{T}}_{\mathrm{S}}$ was $+0.61^{\circ} \mathrm{C}$, $\Delta$ heart $\mathrm{r}$ ate was 34 beats $/ \mathrm{min}$ and the terminal heart rate was $54 \%$ of the maximal he art rate (Table 3). The average sweat rate increased from $66 \mathrm{~g} /\left(\mathrm{hr} \cdot \mathrm{m}^{2}\right)$ during the first half-hour work period to $110 \mathrm{~g} /\left(\mathrm{hr} \cdot \mathrm{m}^{2}\right)$ during the fourth halfhour period. 


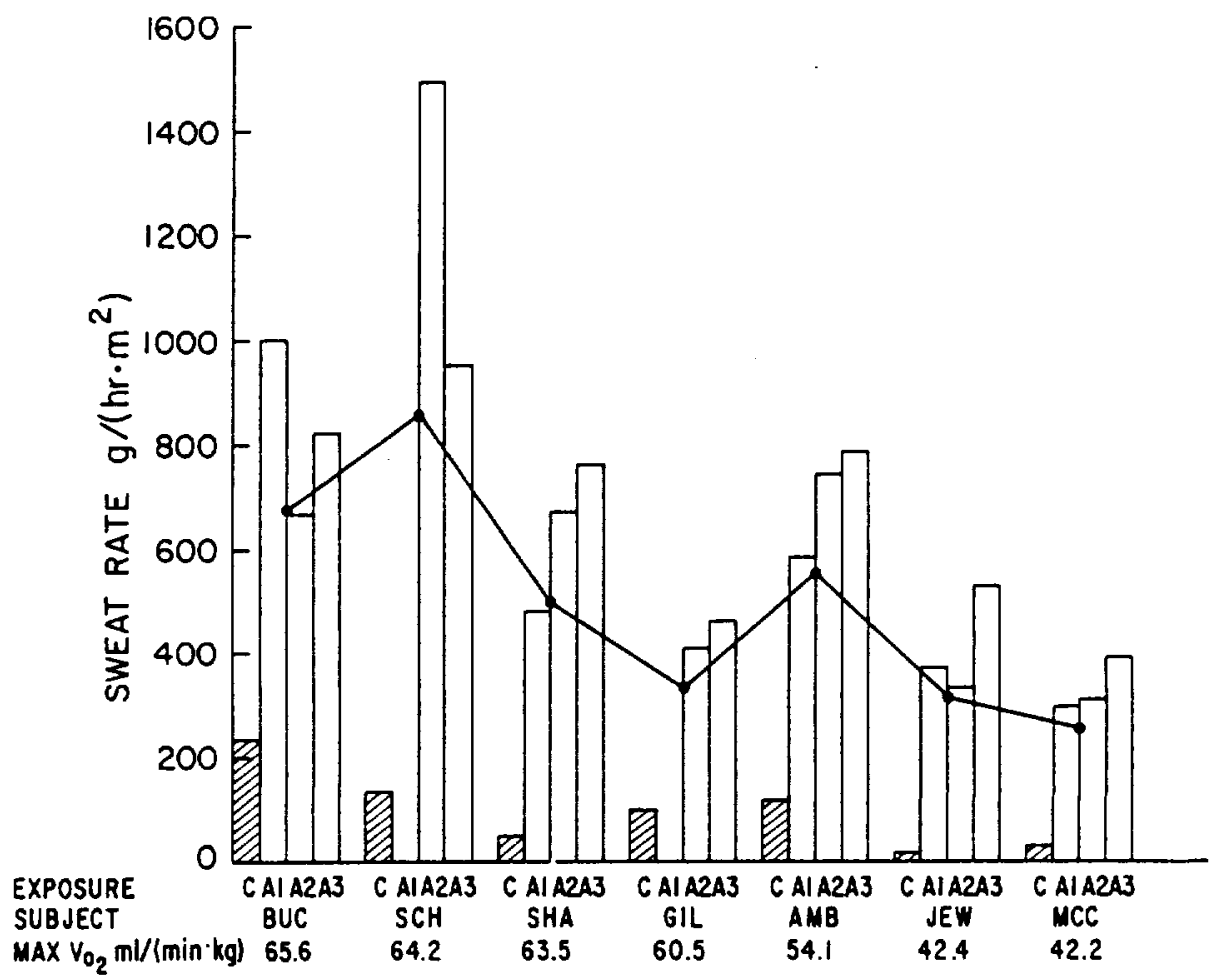

Fig. 3. Individual values during the second half $\mathrm{hr}$ of work for sweating during the control (C) and the acclimation (A1, A2, A3) exposures: the solid line connects the average of the four values. Missing data due to subjects inability to complete work task.

the first interest ig the line is $\mathrm{g}$ the lity of control cts Lximum iree i expoortional

$.61^{\circ} \mathrm{C}$ maxi$\mathrm{r} \cdot \mathrm{m}^{2}$ half-
TABLE 4. Average body temperatures and sweat rates for the two subjects with high max $V_{02}$ and low max $V_{02}$ during the control and acclimation exposures $(t=$ terminal values $)$

\begin{tabular}{l|c|c|c|c|c}
\hline & $\mathrm{T}_{\mathrm{re}}$ & $\Delta \mathrm{T}_{\mathrm{re}}$ & $\mathrm{T}_{\mathrm{s}_{\mathrm{t}}}$ & $\Delta \mathrm{T}_{\mathrm{s}}$ & Sweat rate \\
\cline { 2 - 6 } & $\mathrm{C}$ & $\mathrm{C}$ & $\mathrm{C}$ & $\mathrm{C}$ & $\mathrm{g} /\left(\mathrm{hr} \cdot \mathrm{m}^{2}\right)$ \\
\hline Control & & & & & \\
$\quad$ High max & 37.54 & 0.52 & 31.30 & 0.72 & 178 \\
Low max & 37.56 & 0.15 & 32.56 & 0.18 & 24 \\
Acclimation no 1 & & & & & \\
High max & 39.04 & 1.82 & 39.50 & 2.19 & 996 \\
Low max & 39.04 & 1.73 & 39.90 & 1.26 & 336 \\
Acclimation no 2 & & & & & \\
High max & 39.74 & $2.5 \mathrm{j}$ & 39.82 & 2.46 & 1.092 \\
Low max & 39.28 & 1.98 & 39.70 & 1.20 & 322 \\
Acclimation no 3 & & & & & \\
High max & 39.38 & 1.11 & 39.39 & 2.17 & 884 \\
Low max & 39.25 & 1.10 & 39.42 & 1.18 & 460 \\
\hline
\end{tabular}


During the first acclimation exposure, the average tolerance time was $76 \mathrm{~min}$, $\Delta \mathrm{T}_{\text {re }}$ was $+2.00^{\circ} \mathrm{C}, \Delta \mathrm{T}_{\mathrm{S}}$ was $+1.75^{\circ} \mathrm{C}$ and $\Delta$ heart rate was 79 beats $/ \mathrm{min}$.

A comparison of average data between the first and third acclimation exposures at the point of exhaustion shows that some measurements were remarkably constant: terminal $\mathrm{T}_{\mathrm{re}}\left(39.28^{\circ} \mathrm{C}\right.$ vs $\left.39.26 \mathrm{O}^{\circ} \mathrm{C}\right), \Delta \overline{\mathrm{T}}_{\mathrm{S}}\left(+1.74^{\circ} \mathrm{C}\right), \Delta \mathrm{T}_{\mathrm{re}}\left(2.0^{\circ} \mathrm{C}\right.$ vs $2.1^{\circ} \mathrm{C}$ ) terminal heart rate (162 vs 160 beats $/ \mathrm{min}$ ), $\Delta$ heart rate (79 vs 79 beats/ $\mathrm{min})$, and terminal heart rate in percent of maximum $(83 \%$ vs $82 \%)$. The more variable measurements were: tolerance time in percent of maximum increased from $63 \%$ to $69 \%$, terminal $\mathrm{T}_{\mathrm{S}}$ decreased from $39.75^{\circ}$ to $39.29^{\circ} \mathrm{C}$ and first period sweat rates increased $20 \%$, from 337 to $419 \mathrm{~g} /\left(\mathrm{hr} \cdot \mathrm{m}^{2}\right)$. Some possible criteria for tolerance limits might be constructed from these data: rectal temperature of $39.3^{\circ} \mathrm{C}$; heart rate of 160 beats $/ \mathrm{min}(82 \%$ of maximum); and a change in heart rate of $80 \mathrm{beats} / \mathrm{min}$.

\section{DISCUSSION}

Men with high maximal oxygen uptake are capable of performing heavier work for longer periods of time than lower capacity men. The greater metabolic heat produced by the high capacity men, resulting from the greater absolute work loads, must be dissipated or hyperprexia would occur. Therefore, men with high aerobic capacity must have high heat loss capability or they will not be able to work near their maximal levels.

The results of the present study indicate that near maximal sweat rates, induced by mild exercise in the heat, are proportional to the maximal oxygen uptake. Subjects with maximal oxygen uptakes of $64 \mathrm{ml} /(\mathrm{min} \cdot \mathrm{kg})$ had maximal sweat rates of 884 to $1,092 \mathrm{~g} /\left(\mathrm{hr} \cdot \mathrm{m}^{2}\right)$ while those with maximal oxygen uptakes of $42 \mathrm{ml} /$ $\left(\mathrm{min} \cdot \mathrm{kg}\right.$ ) had maximal sweat rates of 336 to $460 \mathrm{~g} /\left(\mathrm{hr} \cdot \mathrm{m}^{2}\right)$ (Table 4$)$. The lower sweat rates in the lower capacity subjects were not due to lower tolerance times in the heat (Fig. 2, upper left). During the control exposure at $\mathrm{T}_{\mathrm{db}} 25^{\circ} \mathrm{C}$ average sweat rate was $96 \mathrm{~g} /\left(\mathrm{hr} \cdot \mathrm{m}^{2}\right)$ but the high capacity subjects (BUC, SCH, SHA) had sweat rates between 49 and $228 \mathrm{~g} /\left(\mathrm{hr} \cdot \mathrm{m}^{2}\right)$ while the lower capacity men (JEW, $\mathrm{McC})$ sweated between 17 and $31 \mathrm{~g} /\left(\mathrm{hr} \cdot \mathrm{m}^{2}\right)$. Thus the exercise per se contributed less than 20 percent of the maximal sweat rates during exercise in the heat.

Saltin and Hermansen (1966) suggested there was a direct relationship between maximal oxygen uptake and the rate of sweating during moderate exercise at $24^{\circ} \mathrm{C}$ ambient temperature. Two men with widely different maximal oxygen uptakes and working at the same relative oxygen uptakes but different absolute work loads had the same equilibrium levels of rectal temperature. Since the higher capacity subject had greater heat production because of his greater work load than the lower capacity subject, the "excess" heat from the former had to be dissipated for the rectal temperatures to attain the same level. The "excess" heat was dissipated mainly through greater evaporative loss since the exercise sweat $r$ ate of the high capacity subject was about $60 \%$ greater than that of the lower capacity man. In the present study the subjects worked at essentially the same relative oxygen uptakes but dry-bulb temperature was elevated to elicit maximal sweating. There is a positive relationship between the rate of sweating and maximal oxygen uptake with either a moderately heavy load in a cool environment (Saltin and Hermansen, 1966), resting in a sauna bath (Kozlowski and Saltin, 1964) or with a mild work load in the heat (present study). These observations suggest that as long as there is a stimulus sufficient to initiate sweating, this relationship between sweating and maximal oxygen uptake is not specifically dependent upon work load, metabolic rate or ambient temperature.

To explain the greater exercise sweating with high maximal oxygen uptakes in men who have the same equilibrium levels of core and skin temperature as lower 
capacity men, Saltin and Hermansen (1966) suggest that any mechanism responding directly with the individual max $\dot{V}_{02}$ or the absolute work load, for example mechanoreceptor function, may provide stimuli that results in increased sweating. Smiles and Robinson (1971) present evidence that the level of exercise sweating is controlled by an undefined stimulus proportional to oxygen uptake (metabolic rate) plus a neuromuscular stimulus proportional to the speed of muscular movement (walking). However, other evidence suggests mechanoreceptor function is probably not an important part of the mechanism (Ekblom, Greenleaf and Hermansen, 1971; Greenleaf et al., 1971; Nielsen, 1968).

In the present study the high correlation between maximal oxygen uptake and sweating during work in heat could not have been influenced by speed of movement since there was a constant rate of pedaling the ergometer. The greater sweating in our higher capacity subjects was not related in any consistent pattern to terminal $T_{r e}, \Delta T_{r e}$ or terminal $\bar{T}_{S}$. The high capacity subjects did exhibit a twofold greater $\Delta T_{\mathrm{s}}$ during the control and heat exposures compared with the low capacity men (Table 4 ). Since terminal $\bar{T}_{S}$ were the same in the two groups, the difference in $\Delta \bar{T}_{S}$ was due to different resting skin temperatures (Table 3 ). The higher $\overline{\mathrm{T}}_{\mathrm{S}}$ in the low capacity group was probably due to their lower sweat rates in the rest period before exercise commenced (Kozlowski and Saltin, 1964). Thus, we are left with a still undefined mechanism for the observed relationship between maximal oxygen uptake and maximal sweating.

In normal, ambulatory people, exercise training of progressively increasing intensity can increase maximal oxygen utilization only 15 to 20 percent (Ekblom, 1969). Bed rest deconditioning reduces $\max \dot{V}_{02}$ up to 100 percent (Saltin et al., 1968). Maximal rates of sweating have not been measured in deconditioned subjects. It is possible that heredity sets the upper and perhaps also the lower limits of the oxygen uptake capacity from training and deconditioning. If the rate of sweating is coupled directly with the oxygen uptake capacity, then perhaps genetic factors influence the limits of sweating. It is also possible that both maximal oxygen uptake and maximal sweating are responding to a third common unknown variable or mechanism.

There was no appreciable difference between the responses of our high capacity and low capacity subjects to endurance, $\Delta$ heart rate, $\Delta \mathrm{T}_{\mathrm{re}}$ or terminal heart rate during the control and heat exposures (Fig. 2). But, there was a large difference in rates of sweating. These results modify observations from earlier studies that fit men exhibited more favorable responses to initial work in the heat than less fit men. One reason for this discrepancy is that in each of the earlier studies all subjects worked at the same absolute load during the acclimation exposures. Since the more fit men probably had higher maximal oxygen uptakes, they would have been working at lower relative loads, hence the attenuated physiological responses and greater performance. The similar endurance performances of our high and low capacity subjects appear to be the result of similar relative loads, in spite of wide variations in sweating. These results question the importance of the rate of sweating as a major determinant of performance during early heat exposure but affirm the close relationship between maximal oxygen uptake and the capacity to maintain thermal homeostasis. 
ASTRAND, I. (1960)

: Aerobic work capacity in men and women with special reference to age. Acta Physiol. Scand., suppl. 169.

BEAN, W. B. and EICHNA, L.W. (1943): Performance in relation to environmental temperature. Reactions of normal young men to simulated desert environment. Fed. Proc. 2: $144-158$

BRADBURY, P.A., FOX, R.H., GOLDSMITH, R. and HAMPTON, I.F.G. (1964): J. Physiol. (Lond.), $171:$ 384-396.

DILL, D. B. and FÖLlING, A. (1928): Studies in muscular activity. II. A nomographic description of expired air. Amer. J. Physiol. $66: 133-135$.

EICHNA, L.W., BEAN, W.B., ASHE, W.F . and NELSON, N. (1945): Performance in relation to environmental temperature. Reactions of normal young men to hot, humid (simulated jungle) environment. Bull. Johns Hopk. Hosp., $76: 25-58$.

EKBLOM, B. (1969) : Effect of physical training on oxygen transport system in man. Acta Physiol. scand., suppl. 328.

EKBLOM, B., GREENLEAF, C.J. and HERMANSEN, L. (1971): Temperature regulation during continuous and intermittent exercise in man. Acta Physiol scand, $81: 1-10$.

GREENLEAF, J.E. (1964): Lack of artificial acclimatization to heat in physically fit subjects. Nature (Lond.), $203: 1072$

GREENLEAF, J.E . and CASTLE, B.L. (1972): External auditory canal temperature as an estimate of core temperature. J. appl. Physiol., $32: 194-198$.

GREENLEAF, J.E., KESSEL, A.L.van, RUFF, W. , CARD, D.H. and RAPPORT, M. (1971)

: Exercise temperature regulation in $m$ an in the upright and supine positions. Med. Science Sports, $3: 175-182$

KOZLOWSKI, S. and SALTIN, B. (1964): Effect of sweat loss on body fluids. J. appl. Physiol., $19: 1119-1124$.

NIELSEN, B. (1968) : Thermoregulatory responses to arm work, leg work and intermittent leg work. Acta Physiol. Scand., $72: 25-32$.

PIWONKA, R. W., ROBINSON, S., GAY, V.L. and MANALIS, R.S. (1965): Preacclimatization of men to heat by training. J appl. Physiol., 20 : 379-384.

ROWELL, L.B., KRANING II, K.K., KENNEDY, J.W. and EVANS, T. O. (1967): Central circulatory responses to work in dry heat before and after acclimatization. J. appl. Physiol., $22: 509-518$.

SALTIN, B., BLOMQVIST, B., MITCHELL, J.H., JOHNSON, JR., R. L.,

WI LDE NTHAL, K. and CHAPMAN, C.B. (1968): Response to exercise after bed rest and after training. Circulation, 38 : suppl. $7: 1-78$.

SALTIN, B. and HERMANSEN, L. (1966): Esophageal, rectal, and muscle temperature during exercise. J. appl. Physiol., $21: 1757-1762$.

SCHOLANDER, P.F. (1947): Analyser for accurate estimation of respiratory gases in one-half cubic centimeter samples. J. biol. Chem., $167: 235-250$. 
SMILES, K.A. and ROBINSON, S. (1971): Regulation of sweat secretion during positive and negative work. J. appl. Physiol.,

men with

l. Sc and.,

1 to environmal young men 1. Proc. 2:

J. I.F.G. (1964):

;y. II. A nomoner. J. Physiol.

945): Performperature. , humid (simns Hopk. Hosp.,

iransport sysippl. 328.

Temperature mittent exer$1: 1-10$. eat in physi$3: 1072$. - canal temperure. J. appl.

I. and RAPan in the upnce Sports,

sody fluids.

rork, leg work

ol. Scand.,

S. (1965): Preting. J. appl.

NS, T. O. (1967): in dry heat spl. Physiol.,

2., R. L., rcise after bed 8 : suppl.

d muscle Physiol., respiratory nples.
$30: 409-412$.
STRYDOM, N.B., WYNDHAM, C.H., WILLIAMS, C.G., MORRISON, J.F., BREDELL, G.A.G., BENADE, A.J.S. and von RAHDEN, M. (1966): Acclimatization to humid heat and the role of physical conditioning. J. appl. Physiol., $21: 636-642$.

WYNDHAM, C.H., BENADE, A.J.A., WILLIAMS, C.G., STRYDOM, N.B., GOLDIN, A. and HEYNS, A.J.A. (1968): Changes in central circulation and body fluid spaces during acclimatization to heat. $\mathrm{J}$. appl. Physiol., $25: 586-593$.

ABSTRACT. - The purpose of this experiment was to determine if tolerance to exercise in the heat is related to maximal oxygen uptake $\left(\max \nabla_{02}\right)$ and sweating. Seven men with $\max \dot{V}_{02}$ between 42 and $66 \mathrm{ml} /(\mathrm{min} \cdot \mathrm{kg})$ underwent one $2-\mathrm{hr}$ exposure at $24^{\circ} \mathrm{C} T_{p}$ while working on a bicycle ergometer at $\bar{X}$ rel $\dot{V}_{02}$ of $28 \%$ $\left(\overline{\mathrm{X}} \dot{\mathrm{V}}_{02}=1.23 \mathrm{l} / \mathrm{min}\right)$. In the hot exposures the high capacity subjects had maximal sweat rates of 800 to $1,000 \mathrm{~g} /\left(\mathrm{hr} \cdot \mathrm{m}^{2}\right)$ while the lower capacity men sweated 300 to $400 \mathrm{~g} /\left(\mathrm{hr} \cdot \mathrm{m}^{2}\right)$. These differences in sweating were not related to neuromuscular stimuli, $\dot{\mathrm{V}}_{02}$ (metabolic rate), $\mathrm{T}_{\mathrm{re}}, \Delta \mathrm{T}_{\mathrm{re}}, \mathrm{T}_{\mathrm{S}}, \Delta \overline{\mathrm{T}}_{\mathrm{S}}$ or tolerance time. Tolerance to exercise in the heat was not related to maximal $\dot{V}_{02}$ capacity when the subjects worked at the same relative load in spite of large differences in sweating. These results question the importance of the rate of sweating for predicting work performance in hot environments.

ZUSAMMENFASSUNG. - Das Ziel dieser Untersuchung war, zu prïfen, ob die Toler anz bei Arbeit in der Hitze in einer Beziehung steht zur maximalen $\mathrm{O}_{2}$-Aufnahme und Schwitzen. Sieben Männer mit $V_{02}$ zwischen $+2-66 \mathrm{ml} /(\mathrm{min} \cdot \mathrm{kg})$ wurden belastet wăhrend 2 Stunden bei $\mathrm{T}_{\mathrm{a}} 24^{\circ} \mathrm{C}$ und $3 \times 2$ Stunden bei $47 \circ \mathrm{C} \mathrm{mit}$ Arbeit auf dem Fahrrad-Ergometer bei im Mittel von $28 \% V_{02}=1.23 \mathrm{l} / \mathrm{min}$. Wahrend der Hitzebelastung zeigten die leistungsfahigen Personen Schweissekretionsraten von $800-1000 \mathrm{~g} /\left(\mathrm{hr} \cdot \mathrm{m}^{2}\right)$ und die wenig leistungsfahigen $300-400 \mathrm{~g} /$ $\left(\mathrm{hr} \cdot \mathrm{m}^{2}\right)$. Diese Unterschiede waren ohne Beziehung zu neuromuskulären Stimuli, Stoffwechselrate, $T_{\text {re }}, \Delta T_{\text {re }}, \bar{T}_{s}, \Delta \bar{T}_{S}$ oder der Toleranzzeit. Ausdauer bei Arbeit in der Hitze war ohne Beziehung zur maximalen $\mathrm{V}_{02}$-Kapazităt, wenn die Personen bei der gleichen relativen Belastung arbeiteten tro grosser Unterschiede im Schwitzen. Die Ergebnisse stellen den Wert der Schweissekretionsrate zur Voraussage der Arbeitsleistung in der Hitze in Frage.

RESUME. - Dans cette étude, on a cherché a voir si la tolérance au travail sous contrainte de chaleur était en relation avec la possibilité maximum d'absorption de $\mathrm{O}_{i}\left(\mathrm{~V}_{02}\right)$ d'une part, de transpirer d'autre part. 7 hommes présentant des $\dot{\mathrm{V}}_{02}$ compris entre 42 et $66 \mathrm{ml} /(\mathrm{min} . \mathrm{kg}$ ) ont pédalé sur un ergometre pendant 2 heures par une $\mathrm{T}$ de $24^{\circ} \mathrm{C}$ et $3 \times 2$ heures par $47^{\circ} \mathrm{C}$ et cela par une $\dot{\mathrm{V}}_{02}$ relative de $28 \%$ ( $\left.\overline{\mathrm{X}}_{02}=1,251 / \mathrm{min}\right)$. Durant l'effort sous contrainte de chaleur, les plus actifs ont eu des sécrétions de sueur de $800 \mathrm{2} 1.000 \mathrm{~g} \mathrm{~h}^{-1} \mathrm{~m}^{-2}$ et les moins actifs de $300 \mathrm{a} 400 \mathrm{~g} / \mathrm{h} . \mathrm{m}^{2}$. Ces différences étaient sans rapport avec les stimulus neuro-musculaires, le taux de métabolisme, $T_{r e}, \Delta T_{r e}, T_{s}$ et $\Delta T_{s}$ ou la durée de tolérance. L'endurance au travail sous contrainte de chaleur n'a pas été fonction de la capacité maximum de $\dot{V}_{02}$, lorsque les personnes travaillaient dans des conditions analogues, même si l'on a noté de grandes différences dans la transpiration. Ces résultats mettent en doute la représentativité du taux de sécrétion de sueur comme indicatif des possibilités de travailler en atmosphère chaude. 